Applied Psycholinguistics (1989) 10, 49-66

Printed in the United States of America

\title{
Life-span changes to adults' language: Effects of memory and genre
}

\author{
SUSAN KEMPER, DONNA KYNETTE, SHANNON RASH, \\ and KEVIN O'BRIEN \\ University of Kansas \\ RICHARD SPROTT \\ University of California, Berkeley
}

ADDRESS FOR CORRESPONDENCE

S. Kemper, 426 Fraser Hall, University of Kansas, Lawrence, KS 66045

\begin{abstract}
Three different language samples were collected from a group of young adults, 18 to 28 years of age, and a group of elderly adults, 60 to 92 years of age: an oral questionnaire eliciting information about the adults' background, education, and current health and activities; an oral statement describing the person they most admired; and a written statement recounting the most significant event in their lives. In addition, the WAIS vocabulary and digit-span tests were administered to the adults. Age-related changes in the length, clause structure, and fluency of the adults' oral answers and oral and written statements were investigated. There was an overall decrement in the complexity of adults' oral and written statements attributable to an age-related loss of left-branching clauses which occurred in all three language samples. Correlations between the length, clause, and fluency measures from the language samples and the education, health, and WAIS vocabulary and digit-span tests revealed that better-educated adults scored higher on the WAIS vocabulary test, produced longer utterances, and used more right-branching clauses, and that adults with greater memory capacity, as measured by the WAIS Digits Backward test, produced more complex utterances and used more right- and left-branching clauses. Judges found the statements from the elderly adults to be more interesting and clearer than those from the young adults. This finding suggests that there is a trade-off between producing complex syntactic structures and producing clear and interesting prose.
\end{abstract}

Despite the interest of psychologists, speech-language-hearing scientists, linguists, and educators in language development in children, language development during the adult years has received little attention (Cohen, 1981). While we now know a great deal about language development in preschool and school-age children, we commonly assume that language development "crystalizes" sometime during adolescence and, apart from the consequences of hearing loss, brain trauma, or dementia, remains uniform across the life-span. However, this assumption is not warranted in light of an 
emerging body of research that examines life-span changes to adults' language (Obler, 1983, 1985).

Careful studies of adults' language and comprehension do reveal agerelated decrements for text comprehension and recall (Cohen \& Faulkner, 1984; Zelinski \& Gilewski, in press) and for the repetition and production of complex syntactic constructions (Emery, 1985; Kemper, 1986, 1987a, 1987b, in press; Kynette \& Kemper, 1986).

Kemper (1988) and Kemper and Rash (1988) suggested that such performance decrements are due to working memory limitations which affect adults' ability to retain and manipulate multiple syntactic elements simultaneously. Working memory limitations (Baddeley, 1985) may arise because of limitations on adults' capacity to analyze discontinuous morphemes, strategic differences in how they allocate attention to processing syntactic relations, or differences in the speed with which they can perform such elementary operations as establishing the antecedents of pronouns.

The present study was designed to replicate and extend the research of Kemper (1988) and Kynette and Kemper (1986) by examining the oral and written language of adults aged 60 and above. In particular, the study seeks (a) to determine sources of individual variation in adults' language by examining how education, memory ability, vocabulary, and health affect adults' language and (b) to investigate whether the syntactic complexity of adult's language varies from one discourse genre to another.

We hypothesized that working memory limitations would affect adults' production of such complex grammatical structures as embedded infinitive complements, relative clauses, and gerunds. In particular, we expected to find that there is an overall age-related decrement in the complexity of adults' speech, but that this decrement is more precipitous for left-branching embeddings than for right-branching ones. We expected this asymmetry in producing left- and right-branching clauses because left-branching clauses, in general, impose greater demands on working memory than right-branching ones (Kemper \& Rash, 1988).

We also hypothesized that the differential processing demands of discourse genres would affect adults' production of complex grammatical structures. In this study, three discourse genres were compared: oral question-answering involving adults' responses to questions about their employment history and current activities, an oral expository statement requiring them to describe "the person they most admire," and a written expository statement requiring them to write a short description of "the most significant event" in their life.

A concern with syntactic complexity has been central to the study of discourse processing; some researchers have suggested that oral discourse is syntactically simpler than written discourse (Kroll, 1977; O'Donnell, 1974) due to different processing demands of the two modalities. Ochs (1979) suggested that written discourse requires more "planning time" in order to carefully and exactly specify the relationships among ideas and that leads to a higher incidence of complex coordinate, subordinate, and embedded constructions. 
Beaman (1984), Chafe (1982), and Tannen (1982) take issue with the notion of a dichotomy between oral and written discourse and suggest instead that there is a continuum. Chafe (1982) has proposed that syntactically complex prose occurs more frequently in written discourse than in oral discourse because writers are more detached and less involved with their audiences than are speakers. Chafe goes on to suggest that the continuum of involvement-to-detachment leads to a continuum of fragmentation-to-integration in syntax; involved, fragmented discourse is characterized by many repetitions, fragments, and false starts, whereas detached, integrated discourse has many embedded and subordinate constructions. Oral discourse is typically highly fragmented and involved, whereas written discourse is highly integrated and detached.

The three elicitation tasks used in the present study were selected so as to span this continuum of involved/fragmented to detached/integrated discourse. Oral question-answering was expected to yield the least complex syntax with the fewest embedded and subordinate constructions, reflecting limited planning time and greater speaker-audience involvement. The written expository statements were expected to have the most complex syntax, with the greatest use of embeddings and subordination reflecting increased planning time and greater detachment of writer and audience. The syntactic complexity of the oral expository statements was expected to be intermediate, lying between these two extremes.

Age-group interactions were also expected across this continuum of discourse genres. Elderly adults' speech was expected to resemble that of young adults for the syntactically simple, highly involved oral question-answering. In contrast, age-group differences were expected to increase across the involvement-to-detachment continuum, reflecting an increase in the syntactic complexity of the young adults' discourse but no increase in the syntactic complexity of the elderly adults' discourse. The written expository prose of the young adults was expected to be syntactically more complex than their oral question-answering; in contrast, the written expository prose of the elderly adults was expected to be as syntactically simple as their oral question-answering. Such a pattern would indicate that elderly adults are unable to overcome working memory limitations which hinder their production of complex syntactic constructions in written discourse despite the greater planning time that writing affords.

\section{METHOD}

\section{Subjects}

Thirty young adults (including 17 women) who were native speakers of English, 18 to 28 years old $(M=21.4)$, were recruited from introductory psychology classes. Eighty-seven elderly adults, 60 to 92 years of age, were recruited from the local community through newspaper advertisements. Of these, 7 were judged not to be native speakers of English because they spoke a language other than English before age 5. Of those considered to be native 
speakers of English, data from 2 adults was incomplete, so that the final sample consisted of 37 adults (24 women) 60 to 69 years $(M=65.3), 26$ adults ( 18 women) 70 to 79 years $(M=73.9)$, and 15 adults ( 10 women) 80 to 92 years $(M=83.9)$. The young adults received course credit for their participation; the elderly adults were paid for their participation.

\section{Interview}

Each subject was interviewed individually. The interviews lasted 30 to 50 minutes and consisted of three parts: First, an oral questionnaire was used to elicit information about the adults' background, education, and current health and activities. This questionnaire concluded by asking the adults to orally describe the person they most admired. Second, the Vocabulary test and Digits Forward and Digits Backward tests from the Wechsler Adult Intelligence Test - Revised (Wechsler, 1958) were administered. Third, each adult was asked to write a short essay to describe the most significant event in their lives. Each interview was audio recorded so that language samples from the oral questionnaire could be transcribed and coded.

The questionnaire elicited the adults' place and date of birth, the number of years of formal education completed, their employment history, and current activities and interests. In addition, the adults were asked for selfreport assessments of their overall health, vision, hearing, and mobility using a three-point scale of $(-1)$ worse than, (0) same as, or $(+1)$ better than other adults their age. The standard scoring conventions were used for the WAIS scales. For the Digits Forward and Digits Backward tests, 1 point was given for each list of a specified length that was repeated correctly, for a maximum score of 14 on each test. For the Vocabulary test, 2 points were given for each complete definition and 1 point for each partial definition for a maximum score of 70 .

\section{Language samples}

Two oral language samples were obtained from the interview. The first was a sample based on the adults' answers to a fixed series of questions about their employment history and current activities. A maximum of 50 consecutive utterances was transcribed for later analysis. The second oral language sample was the adults' response to the question, "What person, living or dead, famous or not, do you admire the most and why?" The adults' complete response was transcribed. A written language sample was obtained from the adults' written response to the question: "Please write a short passage about the most significant event you've experienced. It could be about the best thing that ever happened to you or it could be about the worst thing that ever happened."

\section{Transcription and coding}

The language samples were transcribed and coded by first segmenting each into utterances and then coding each utterance. In general, conventional 
sentence boundaries marked one utterance from another. Utterances were not restricted to sentences; sentence fragments corresponding to incomplete sentences, rephrasings or revisions of the previous utterance, or additions to the previous utterance following a pause, and both lexical and nonlexical fillers were all considered as separate utterances. Since sentences or other utterances might involve "word-finding" problems (Burke, Worthley, \& Martin, 1988), utterances in which the same basic thought or idea was completed following a pause (which might be filled with a nonlexical "uh" or similar filler) were considered as one utterance. Continuations or rephrasings that added new information to a previous complete sentence following a pause were considered as separate utterances.

Lexical fillers such as "well," "yeah," or "let's see" were transcribed as separate utterances if they occurred at the beginnings or ends of another utterance. Lexical fillers that occurred within another utterance were transcribed as part of the utterance.

Unintelligible or partially unintelligible utterances were excluded from the sample. Nonlexical fillers that occurred within utterances or that were used between utterances such as "uh," "uh-uh," "um," or "duh," were also excluded from the sample. Utterances that repeated or echoed remarks by the experimenter or repeated or echoed the adults' previous remarks were also excluded.

Each utterance was coded in terms of the type of clauses it contained and also coded as to whether it was a complete sentence or a sentence fragment. Clauses were identified as either main clauses, left-branching subordinate or embedded clauses, or right-branching subordinate or embedded clauses. Main clauses have both a subject and predicate, are inflected for tense, and can be linked together in a series with conjunctions. Within utterances, only the initial verb of coordinate predicates sharing a common subject was coded as a main clause. Subordinate clauses are left-branching or rightbranching in relation to the predicate of the main clause, and are marked with a conjunction like "since," "because," or "although." Subordinate clauses also have a subject and predicate and are inflected for tense. Embedded clauses that occur are also either left-branching or right-branching in relation to the predicate of the main clause. Common forms include that-clauses, wh-clauses, relative clauses, infinitive complements, and gerunds. Embedded clauses are commonly introduced by a grammatical marker such as the word "to," which marks infinitives, or relative pronouns, which mark relative clauses. Many embedded clauses, such as infinitives, are uninflected for tense. Some subordinate and embedded clauses, particularly those occurring in sentence fragments, could not be classified as leftor right-branching.

Two types of fragments were distinguished from complete sentences. The first type was fragments that were missing their subject, usually the speaker or the subject of the immediately previous sentence. All other sentence fragments were categorized together. Either type of fragment could have involved one or more subordinate or embedded clauses; if possible, such subordinate or embedded clauses were coded as sentence-initial or sentencefinal with regard to the main predicate of the sentence fragment. Examples are given in Table 1 . 
Kemper et al.: Adults' language

Table 1. Example transcript indicating main (MAIN), subordinate (SUB), infinitive phrases (INF), relative clauses (REL), that-clauses (THAT), wh-clauses (WH), and gerunds (GER). Each subordinate or embedded clause is marked as left-branching (L) or right-branching (R). Fillers (FILL), sentence fragments without subjects (w/o $S U B J)$, and other types of sentence fragments (FRAG) are also indicated.

As a young person I worked [MAIN] in Salina in the state grain inspection office for summer jobs.

And did [MAIN] that some in college too [w/o SUBJ]

And I worked [MAIN] one summer in Kansas City.

Actually it was required [MAIN] for my degree.

It was [MAIN] a seminar and we worked [MAIN] in [FRAG] (pause)

Not a seminar, but a practical experience [FRAG] (pause)

And I worked [MAIN] in city hall in the personnel office in city hall and actually they let [MAIN] me come [INF-R] in and sit [INF-R] at a desk.

Then [FILL] (pause)

Then I was married [MAIN] and [FRAG] (pause)

Had [MAIN] children [w/o SUBJ] (pause)

And [FILL] (pause)

When they were grown [SUB-L] I started [MAIN] working [GER-R] in the school system here.

First as a volunteer [FRAG]

And when I realized [SUB-L] they were paying [THAT-L] someone for essentially what I was doing [WH-L] why [FILL] I applied [MAIN] and got a job as an aide.

This was [MAIN] with specialized children.

Yeah [FRAG]

It was [MAIN] very interesting actually and I enjoyed [MAIN] it a lot.

I am [MAIN] now divorced and after I was divorced [SUB-L] I started [MAIN] working [GER-R].

I worked [MAIN] in two different banks here in Lawrence and now work in an attorney's office.

No [FRAG]

I thought [MAIN] being [GER-R] very naive that when I got [SUB-R] back into the world as a person aspiring [GER-R] to have [INF-R] a job that probably I would be able [THAT-R] to, but I was [MAIN] not realistic.

\section{Reliability}

Reliability for three different aspects of the coding was assessed. First, transcription reliability was assessed by comparing five transcripts prepared by three different judges. For these transcripts, interjudge reliability averaged $95 \%$ for segmenting the interviews into utterances. Second, reliability was assessed for the identification of fillers, both types of sentence fragments, and complete utterances. Interjudge reliability was better than $98 \%$ agreement. Third, reliability was assessed for the coding of main clauses, subordinate clauses, right- and left-branching clauses, and other types of clauses. Interjudge agreement was better than $98 \%$ for these different types of clauses. 
Kemper et al.: Adults' language

Analysis

Each language sample was analyzed using the Systematic Analysis of Language Transcripts (SALT) computerized system developed by Chapman and Miller (1984). Two measures of sentence length were computed: the mean number of words per utterance (MLU) and the mean number of clauses (main, subordinate, and embedded) per utterance (MCU). Second, four measures of clause structure were computed: the percent of sentence-initial or left-branching subordinate or embedded clauses (LEFT), the percent of sentence-final or right-branching embedded or subordinate clauses (RIGHT), the percent of other subordinate or embedded clauses that could not be classified as to position (OTHER), and finally, the percent of main clauses (MAIN). Third, four measures of fluency were computed: relative to the total number of utterances, the percentage that were sentence fragments missing subjects (w/o SUBJECT), the percentage that were all other types of sentence fragments (FRAGMENT), the percentage that contained lexical fillers (FILLER), and the percentage that were complete sentences (COMPLETE).

\section{Oral and written statements}

A final analysis examined the organization and content of the oral and written statements. The transcripts of these statements were distributed to a group of 12 undergraduate students and a second group of 6 adult judges. The undergraduate judges ( $M=18.6$ years) were enrolled in an introductory psychology class and were naive with respect to the purposes or design of the study. The adult judges ( $M=73.5$ years) were recruited through personal contacts from the local community; none had previously participated in studies of language development across the life-span and all were naive with respect to the purposes or design of the study.

Each judge rated the statements on two scales. The first rating scale ranged from (1) poorly organized, hard to follow to (7) clear, well organized. The second rating scale ranged from (1) dull, boring to (7) very interesting. Each judge rated either 108 oral or 108 written statements. Each judge was given one of two booklets; one booklet contained the 108 oral statements and the other contained 108 written statements. The statements were randomly ordered in each booklet; two rating scales accompanied each statement. Each statement was thus rated by 6 undergraduate judges and 3 adult judges.

\section{RESULTS}

The data analysis involved four stages. First, the four groups of adults were compared on the basis of the background and WAIS data collected as part of the interview. Second, the language samples were compared so as to examine possible discourse genre and age-group differences. Third, the interview data was correlated with the language sample data to examine indi- 
vidual differences in speaking and writing. Multiple regression was used to predict the measures of syntactic complexity from these individual difference measures. Fourth, the ratings of the oral and written statements were compared and the relationship between these ratings and the adults' use of complex sentences was examined.

\section{Interview data}

The interview data was first used to compare the four groups of adults. In this analysis, there were four age groups: young adults 18 to 28 years, and adults 60 to 69 years, 70 to 79 years, and $80+$ years; age group was a between-subjects factor, and years of education completed, health, vision, hearing, and mobility ratings, and scores on the WAIS Digits Forward and Digits Backward and Vocabulary tests were treated as multiple dependent variables. In this analysis, there was a significant multivariate effect, $F(3,104)=3.23, p<.05$, indicating that the groups did differ, and there were significant univariate $F$ s for years of education and overall health. The three groups of elderly adults had completed more years of formal education $(M=14.2$ years) than the college students $(M=13.0$ years $), F(3,104)=6.08$, $p<.01$. The college students reported that their health was the same as that of others their age $(M=.13$ where (0) same as others your age) whereas the elderly adults reported that their overall health was somewhat better $(M=$ .52) than others their age, $F(3,104)=6.26, p<.01$. The three groups of elderly adults did not differ on these measures.

There were also significant univariate effects for two of the WAIS scales. Table 2 summarizes these findings. The age groups did not differ on Digits Forward, $F(3,104)=2.41, p>.05$, but there was an age-related decrement on Digits Backward, $F(3,104)=5.68, p<.01$. On the Vocabulary test, the three groups of elderly adults scored significantly higher than did the young adults, $F(3,104)=3.72, p<.05$.

\section{Language samples}

Separate MANOVAs were performed on the length (MLU and MCU), clause (OTHERs, RIGHTs, LEFTs, and MAINs), and fluency (FILLERs, fragments w/o SUBJECTs, other FRAGMENTs, and COMPLETE sentences) measures obtained from the three language samples. In these analyses, age group was a between-subjects factor, while genre (oral question-answering, oral "admire" statement, and written "event" statement) was a within-subjects factor. Multivariate and univariate $F$ s are reported in Table 3, and genre and age-group means are given in Tables 4 and 5. Post-hoc comparisons were performed using the Scheffe procedure with $\alpha=.05$.

\section{Genre}

There were consistent differences between the three language samples. The written samples contained more words per utterance and more clauses per utterance than did either oral language sample. More left-branching clauses 
Kemper et al.: Adults' language

Table 2. Performance on the three WAIS scales (standard deviations in parentheses)

\begin{tabular}{lrrrrrrrr}
\hline \hline & \multicolumn{7}{c}{ Age Group } \\
& \multicolumn{1}{c}{ Young } & \multicolumn{1}{c}{$60 \mathrm{~s}$} & \multicolumn{2}{c}{ 70s } & $80+$ \\
\hline Digits Forward & 9.2 & $(2.1)$ & 9.5 & $(2.6)$ & 9.8 & $(2.3)$ & 8.0 & $(1.8)$ \\
Digits Backward & 7.8 & $(1.9)$ & 7.4 & $(2.3)$ & 7.1 & $(2.4)$ & 5.1 & $(1.3)$ \\
Vocabulary & 54.4 & $(12.5)$ & 62.3 & $(10.2)$ & 62.6 & $(10.3)$ & 61.5 & $(10.4)$ \\
\hline \hline
\end{tabular}

Table 3. Multivariate and univariate $\mathrm{Fs}$

\begin{tabular}{|c|c|c|c|c|c|c|}
\hline & \multicolumn{2}{|c|}{ Age Group } & \multicolumn{2}{|c|}{ Genre } & \multicolumn{2}{|c|}{$\begin{array}{c}\text { Genre } \times \text { Age } \\
\text { Group }\end{array}$} \\
\hline & $d f$ & & $d f$ & & $d f$ & $F$ \\
\hline Length & $(3,104)$ & 1.99 & $(1,104)$ & $300.45 * *$ & $(3,104)$ & $4.21 * *$ \\
\hline MLU & $(3,104)$ & 2.04 & $(2,103)$ & $989.15^{* *}$ & $(6,206)$ & 2.41 \\
\hline MCU & $(3,104)$ & $3.63^{*}$ & $(2,103)$ & $75.39 * *$ & $(6,206)$ & $2.53 *$ \\
\hline Clause & $(3,104)$ & $3.63^{*}$ & $(1,104)$ & $450.65 * *$ & $(3,104)$ & $3.83 *$ \\
\hline OTHER & $(3,104)$ & .74 & $(2,103)$ & $8.38 * *$ & $(6,206)$ & 1.65 \\
\hline RIGHT & $(3,104)$ & .64 & $(2,103)$ & $457.05 * *$ & $(6,206)$ & 1.25 \\
\hline LEFT & $(3,104)$ & $6.62^{* *}$ & $(2,103)$ & $40.54 * *$ & $(6,206)$ & $4.48 * *$ \\
\hline MAIN & $(3,104)$ & .63 & $(2,103)$ & $1696.64^{* *}$ & $(6,206)$ & 1.20 \\
\hline Fluency & $(3,104)$ & 1.12 & $(1,104)$ & $752.75 * *$ & $(3,104)$ & $4.37 *$ \\
\hline FILLERS & $(3,104)$ & .24 & $(2,103)$ & $37.37 * *$ & $(6,206)$ & .39 \\
\hline w/o SUBJECTS & $(3,104)$ & 1.58 & $(2,103)$ & $32.15 * *$ & $(6,206)$ & .94 \\
\hline FRAGMENTS & $(3,104)$ & 1.30 & $(2,103)$ & $256.36 * *$ & $(6,206)$ & $2.64^{*}$ \\
\hline COMPLETE & $(3,104)$ & .56 & $(2,103)$ & $179.12 * *$ & $(6,206)$ & 2.42 \\
\hline
\end{tabular}

$* p<.05$.

$* * p<.01$.

and right-branching clauses occurred in the written samples than in the oral samples, resulting in fewer main clauses in the written samples than the oral ones. The written samples contained more complete sentences and fewer fillers and sentence fragments.

\section{Age group}

The only significant age-group differences were obtained for the mean number of clauses per utterance and the percentage of left-branching clauses. For these measures as well as the percentage of sentence fragments, there were significant Age Group $\times$ Genre interactions, as summarized in Table 6 .

Overall, the mean number of clauses per utterance declined $13 \%$ across 
Applied Psycholinguistics 10:1

Kemper et al.: Adults' language

Table 4. Comparison of the three language samples (standard deviations in parentheses)

\begin{tabular}{|c|c|c|c|c|c|c|}
\hline Length & $\begin{array}{r}\mathrm{O} \\
\text { que } \\
\text { ansv }\end{array}$ & $\begin{array}{l}\text { ral } \\
\text { tion- } \\
\text { yering }\end{array}$ & “adi & $\begin{array}{l}\text { renre } \\
\text { ral } \\
\text { nire" }\end{array}$ & $\begin{array}{l}\text { Writ } \\
\text { “ever }\end{array}$ & ten \\
\hline $\begin{array}{l}\text { MLU } \\
\text { MCU }\end{array}$ & $\begin{array}{l}6.91 \\
1.16\end{array}$ & $\begin{array}{r}(1.64) \\
(.44)\end{array}$ & $\begin{array}{l}7.32 \\
1.40\end{array}$ & $\begin{array}{r}(2.26) \\
(.61)\end{array}$ & $\begin{array}{r}15.18 \\
2.21\end{array}$ & $\begin{array}{r}(4.68) \\
(.79)\end{array}$ \\
\hline $\begin{array}{l}\text { Clauses } \\
\text { OTHER } \\
\text { RIGHT } \\
\text { LEFT } \\
\text { MAIN }\end{array}$ & $\begin{array}{c}4 \% \\
25 \\
4 \\
66\end{array}$ & $\begin{array}{r}(2) \\
(8) \\
(3) \\
(10)\end{array}$ & $\begin{array}{c}4 \% \\
31 \\
6 \\
58\end{array}$ & $\begin{array}{r}(2) \\
(14) \\
(4) \\
(17)\end{array}$ & $\begin{array}{c}2 \% \\
38 \\
8 \\
51\end{array}$ & $\begin{array}{r}(6) \\
(15) \\
(4) \\
(16)\end{array}$ \\
\hline $\begin{array}{l}\text { Fluency } \\
\text { FILLER } \\
\text { w/o SUBJECTS } \\
\text { FRAGMENTS } \\
\text { COMPLETE }\end{array}$ & $\begin{array}{l}4 \% \\
4 \\
33 \\
63\end{array}$ & $\begin{array}{r}(3) \\
(4) \\
(15) \\
(15)\end{array}$ & $\begin{array}{l}7 \% \\
3 \\
33 \\
64\end{array}$ & $\begin{array}{r}(2) \\
(4) \\
(16) \\
(18)\end{array}$ & $\begin{array}{c}<1 \% \\
2 \\
4 \\
94\end{array}$ & $\begin{array}{r}(3) \\
(2) \\
(5) \\
(15)\end{array}$ \\
\hline
\end{tabular}

Table 5. Comparison of the four age groups (standard deviations in parentheses)

\begin{tabular}{|c|c|c|c|c|c|c|c|c|}
\hline Length & \multicolumn{2}{|c|}{ Young } & \multicolumn{4}{|c|}{$\begin{array}{l}\text { Age Group } \\
70 \mathrm{~s}\end{array}$} & \multicolumn{2}{|c|}{$80+$} \\
\hline $\begin{array}{l}\text { MLU } \\
\text { MCU }\end{array}$ & $\begin{array}{l}9.80 \\
1.39\end{array}$ & $\begin{array}{r}(1.77) \\
(.60)\end{array}$ & $\begin{array}{r}10.15 \\
1.27\end{array}$ & $\begin{array}{r}(2.14) \\
(.21)\end{array}$ & $\begin{array}{r}10.02 \\
1.29\end{array}$ & $\begin{array}{r}(2.61) \\
(.23)\end{array}$ & $\begin{array}{l}8.60 \\
1.23\end{array}$ & $\begin{array}{r}(1.68) \\
(.21)\end{array}$ \\
\hline $\begin{array}{l}\text { Clauses } \\
\text { OTHER } \\
\text { RIGHT } \\
\text { LEFT } \\
\text { MAIN }\end{array}$ & $\begin{array}{c}5 \% \\
30 \\
9 \\
56\end{array}$ & $\begin{array}{l}(3) \\
(8) \\
(4) \\
(9)\end{array}$ & $\begin{array}{c}5 \% \\
29 \\
5 \\
62\end{array}$ & $\begin{array}{l}(4) \\
(7) \\
(3) \\
(8)\end{array}$ & $\begin{array}{c}3 \% \\
30 \\
4 \\
64\end{array}$ & $\begin{array}{l}(1) \\
(7) \\
(2) \\
(8)\end{array}$ & $\begin{array}{c}2 \% \\
27 \\
3 \\
68\end{array}$ & $\begin{array}{l}(2) \\
(7) \\
(2) \\
(9)\end{array}$ \\
\hline $\begin{array}{l}\text { Fluency } \\
\text { FILLER } \\
\text { w/o SUBJECTS } \\
\text { FRAGMENTS } \\
\text { COMPLETE }\end{array}$ & $\begin{array}{c}5 \% \\
3 \\
25 \\
74\end{array}$ & $\begin{array}{r}(3) \\
(2) \\
(10) \\
(11)\end{array}$ & $\begin{array}{c}3 \% \\
3 \\
24 \\
72\end{array}$ & $\begin{array}{r}(2) \\
(2) \\
(10) \\
(11)\end{array}$ & $\begin{array}{c}3 \% \\
4 \\
21 \\
75\end{array}$ & $\begin{array}{r}(2) \\
(3) \\
(10) \\
(9)\end{array}$ & $\begin{array}{l}4 \% \\
3 \\
23 \\
75\end{array}$ & $\begin{array}{r}(2) \\
(1) \\
(9) \\
(10)\end{array}$ \\
\hline
\end{tabular}

the age range, but the MCUs were similar for young and elderly adults for the oral question-answering sample. MCUs for the other two samples showed significant age-related decrements of $23 \%$ and $44 \%$ for the oral and written statements, respectively. For the oral "admire" statements, the age- 
Kemper et al.: Adults' language

Table 6. Significant Age Group $\times$ Genre interactions (standard deviations in parentheses)

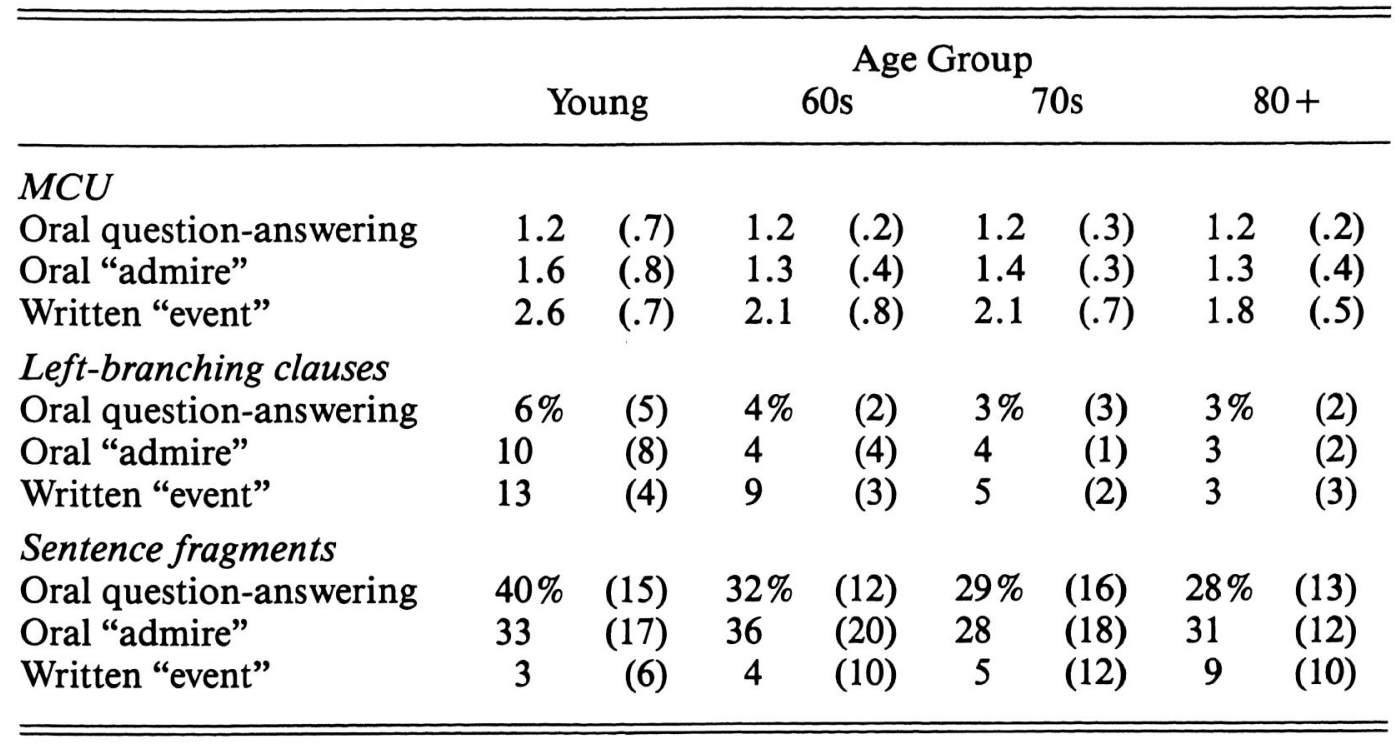

related decrement occurs between the young adults and the adults in their 60 s. For the written "event" statements, the age-related decrement spans the entire age range.

The incidence of left-branching clauses shows an age-related decrement for all three language samples. For oral question-answering and the oral "admire" statements, the decrement shows up between the young adults and the 60-year-olds. For the written "event" statements, the decrement spans the entire age range.

Young adults produced more sentence fragments than did the elderly adults during oral question-answering, but the incidence of sentence fragments is similar for young and elderly adults for the oral "admire" statements and written "event" statements.

\section{Correlations}

The third analysis examined the relationships between the adults' education; ratings of health, vision, hearing, and mobility; Digits Forward, Digits Backward, and Vocabulary scores; and the measures obtained from the language samples. An initial series of analyses computed separate correlations for the three language samples; a similar pattern emerged from the three samples so that the final analysis, reported in Table 7, computed the correlations using average measures collapsing across the language samples. First-order correlations were computed as well as correlations statistically controlling for the effects of age. There were no significant correlations with the self-reported ratings of health, vision, hearing, or mobility, so these variables are not included in Table 7, which reports the partial correlations removing the linear effects of age. 
Applied Psycholinguistics 10:1

Kemper et al.: Adults' language

Table 7. Partial correlations between the language sample measures and the adults' age, years of education completed, and scores on the Vocabulary, Digits Forward, and Digits Backward tests with age partialed out

\begin{tabular}{lllll}
\hline \hline & Education & Vocabulary & Forward & Backward \\
\hline Length & & & & \\
MLU & $+.27^{*}$ & $+.33^{* *}$ & +.15 & +.15 \\
MCU & -.02 & $+.23^{*}$ & $+.27^{* *}$ & $+.22^{*}$ \\
Clauses & & & & \\
Other & -.04 & -.02 & +.02 & +.05 \\
Right-branching & $+.23^{*}$ & $+.21^{*}$ & $+.21^{*}$ & +.11 \\
Left-branching & -.02 & +.16 & $+.46^{* *}$ & $+.49^{* *}$ \\
Main & $-.21^{*}$ & $-.24^{* *}$ & $-.25^{* *}$ & -.16 \\
Fluency & & & & \\
Fillers & -.05 & -.05 & -.15 & -.04 \\
Fragments without subjects & -.09 & $-.29^{* *}$ & $-.20^{*}$ & -.04 \\
Sentence fragments & -.00 & -.13 & $-.21^{*}$ & $-.17^{*}$ \\
Complete sentences & -.02 & $+.21^{*}$ & $+.23^{*}$ & $+.22^{*}$ \\
\hline \hline & & & & \\
$* p<.05$. & & & & \\
$* * p<.01$. & & & & \\
\hline
\end{tabular}

MLU is positively correlated with years of education and score on the WAIS Vocabulary test, whereas MCU is negatively correlated with the adults' age but positively correlated with both WAIS Digits Forward and Digits Backward. These findings suggest that better-educated adults produce longer utterances, as measured in words, but that adults with greater memory capacity produce longer utterances, as measured in clauses.

The use of right-branching clauses is positively correlated with years of education and with vocabulary while main clauses are negatively correlated with education and vocabulary, suggesting that better-educated adults use more right-branching clauses and fewer main clauses. The use of rightbranching clauses is also positively correlated with Digits Forward, while main clauses are negatively correlated with Digits Forward, even when age is controlled, suggesting that adults with greater memory capacity use more right-branching clauses and fewer main clauses. The use of left-branching clauses is positively correlated with both Digits Forward and Digits Backward, even when age is statistically controlled. This suggests that adults with greater memory capacity used more of these clauses.

While the use of complete sentences is positively correlated with vocabulary, Digits Forward, and Digits Backward, fragments without subjects and other types of fragments are negatively correlated with these measures, even when age is partialed out. This suggests that sentence fragments are due to both vocabulary limitations and memory load during sentence production. 
Kemper et al.: Adults' language

Multiple regression was used to test the individual difference measures as predictors of the syntactic complexity of adults' discourse. In these regression analyses, two averaged measures of syntactic complexity were used: the mean number of clauses per utterance averaged over the three language samples and the percentage of left-branching clauses averaged over the three samples. Initially, all the individual difference variables were used as predictors; the final model included only those predictors significantly contributing to the regression equation. For both measures, the adults' backward digit span was an excellent predictor, MCU: $r=.78, r^{2}=.62$, $F(1,107)=175.25, p<.001$; Left-Branches: $r=.94, r^{2}=.88, F(1,107)=$ $802.12, p<.001$. Adding age, years of education, vocabulary, or forward digit span to the regression equation had negligible effects on improving the predictions.

Two other sets of regression analyses were also performed. The second analysis examined the mean length, measured in words, of the adults' utterances averaged across the three samples. For this measure, years of education and vocabulary were significant predictors, $r=.97, r^{2}=.95, F(2,106)=$ $1087.11, p<.001$, with age and either digit span measure adding little to the prediction. The third analysis examined the percentage of right-branching clauses, averaged across the three samples. For this measure, years of education and vocabulary were significant predictors, $r=.68, r^{2}=.37, F(2,106)=$ $8.59, p<.001$; but the addition of backward digit span significantly improved the prediction, $r=.96, r^{2}=.93, F(3,105)=789.64, p<.001$.

\section{Ratings of oral and written statements}

Mean ratings obtained from the ratings of the individual judges for the interestingness and clarity scales are summarized in Table 8. A MANOVA with age group and genre was performed on these ratings; since preliminary analyses revealed no effects of the judges' age group, the ratings from the undergraduate judges and the adult judges were combined in the final analysis. The overall multivariate $F$ s were significant for both main effects as were the univariate $F$ s (Interestingness: Age, $F(3,104)=5.82$; Genre, $F(1,104)=$ 12.86; Clarity: Age, $F(3,104)=4.63$; Genre, $F(1,104)=3.91$; for all $p<$ $.05)$. The Age $\times$ Genre interactions were not significant.

Overall, the written statements were more highly rated than the oral ones. The judges found the elderly adults' statements to be more interesting and clearer than those of the young adults. The increase in interestingness and clarity extended across the entire age range.

Table 9 presents the correlations between these ratings and the individual difference measures and the measures obtained from the language sample analyses, averaged across the three samples. The ratings of interestingness and clarity were strongly correlated $(r(108)=+.84)$. These ratings were averaged and then regression was used to predict these ratings from the individual difference measures and from the measures of length, clause, and fluency obtained from the language sample analyses, averaged across 
Kemper et al.: Adults' language

Table 8. Mean ratings of interestingness and clarity

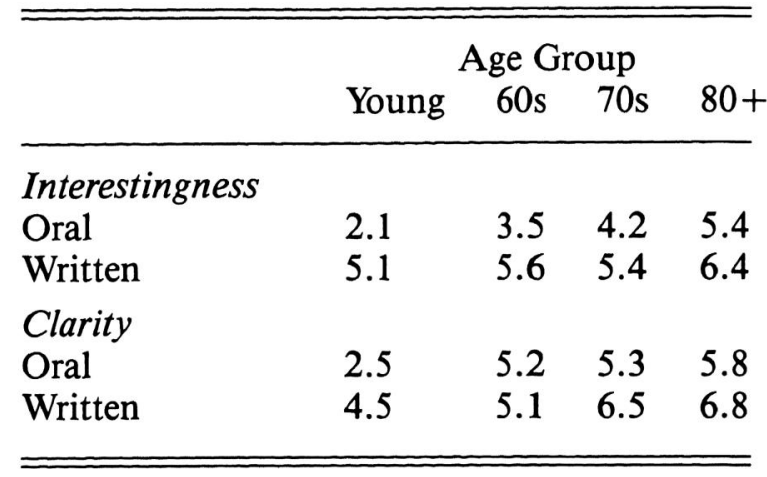

Table 9. Correlations with the ratings of interestingness and clarity

\begin{tabular}{lll}
\hline \hline & Interestingness & Clarity \\
\hline Age & $+.53^{*}$ & $+.57^{*}$ \\
Education & +.03 & +.11 \\
Vocabulary & +.17 & +.15 \\
Forward digit span & +.14 & +.19 \\
Backward digit span & $+.29 *$ & $+.26^{*}$ \\
MLU & -.15 & -.12 \\
MCU & $-.22^{*}$ & $-.24^{*}$ \\
Other clauses & -.04 & -.10 \\
Right-branches & $-.23 *$ & $-.24^{*}$ \\
Left-branches & $-.34^{* *}$ & $-.38^{* *}$ \\
Main clauses & $+.31^{* *}$ & $-.29 * *$ \\
Fillers & -.03 & +.05 \\
Fragments w/o subjects & -.09 & -.00 \\
Sentence fragments & -.04 & +.04 \\
Complete sentences & +.03 & +.11 \\
\hline & & \\
${ }^{*} p<.05$. & & \\
$* *<.01$. & &
\end{tabular}

the three samples. The initial regression model included all of the variables as predictors; the final model included only those predictors that significantly contributed to the equation. In this model, left-branching clauses and MCU were significant predictors of the composite ratings of interestingness and clarity, $r=.84, r^{2}=.71, F(2,106)=50.09, p<.001$. The addition of other variables to this model did not significantly increase $r^{2}$. 
Applied Psycholinguistics 10:1

Kemper et al.: Adults' language

CONCLUSIONS

This study has revealed two different patterns of individual variation in adults' language. On one hand, the oral and written language of bettereducated adults differs from those with less education: they know more words, as measured by the WAIS vocabulary test; and produce sentences containing more words, as measured by MLU, and more right-branching clauses. On the other hand, regardless of educational level, young adults with greater memory capacity (as measured by the WAIS Digits Forward and Digits Backward tests) produce more complex sentences containing more clauses, particularly left-branching clauses (as measured by MCU) than do elderly adults with less memory capacity.

These patterns of individual differences in adults' language are stable across at least three prose genres. Although oral question-answering, oral expository statements, and written expository statements differ in their syntactic complexity, similar effects of education and memory capacity were obtained for all three genres when the language measures were correlated with individual difference measures obtained from the interviews.

The analyses of the language samples from the young adults' confirm Chafe's (1982) ordering of syntactic complexity according to discourse genre. Oral question-answering produced the least complex syntax, whereas written expository statements produced the most complex syntax as indexed by an increase in the mean number of words or clauses per utterance, an increase in the use of right- or left-branching embedded or subordinate constructions, and a decrease in the incidence of sentence fragments.

In contrast, the effect of discourse genre on syntactic complexity was much reduced for the language samples from the elderly adults. The syntactic complexity of the elderly adults' written expository prose (as measured by the mean number of clauses per utterance) and the incidence of left-branching clauses resembled that of their oral question-answering. It appears that the elderly adults were not able to overcome working memory limitations on the production of complex left-branching constructions despite the greater planning time afforded by written discourse.

This interpretation of the simplicity of the elderly adults' discourse is supported by the findings of the correlation and regression analyses. Backward digit span was found to be a significant predictor of both the mean number of clauses per utterance and the incidence of left-branching clauses. Backward digit span presumably measures the capacity of working memory; hence, these results suggest that adults with more working memory capacity used more complex syntactic constructions.

There is an alternative explanation for the pattern of age-group differences in syntactic complexity across the involved-to-detached discourse continuum. It is possible that the increased detachment of writer and audience, leading to syntactically complex written prose by the young adults, is not characteristic of elderly adults. Chafe (1982) suggests that the writer is "less concerned with [conveying the complex details of real experiences], and 
more concerned with producing something that will be consistent and defensible when read by different people at different times in different places" (p. 45). These sorts of concerns may lead young adults to use complex syntactic structures but lead elderly adults to use simple ones. The elderly adults may have avoided using complex syntactic constructions because they had learned that such constructions are difficult for others to understand.

This interpretation is supported by the finding that the elderly adults' expository statements were judged to be more interesting and clearer than the young adults' statements. Further support comes from the correlation and regression analyses, which showed that low ratings of clarity and interest were correlated with the use of complex syntactic constructions. The elderly adults' concern with clarity and interestingness, perhaps triggered by the detachment characteristic of expository prose, may have lead to their use of syntactically simple prose which, in turn, enhanced the clarity and interestingness of their expository statements.

It is likely that both working memory limitations on the production of complex syntactic constructions as well as metalinguistic or stylistic concerns with producing clear and interesting expository statements contributed to the pattern of age-group differences across the three language samples. Indeed, the elderly adults' presumed concern with producing clear and interesting expository statements may have contributed to over-burdening their working memories and, hence, may have further hindered their ability to produce complex syntactic constructions.

Since this research is both correlational and cross-sectional in design, it has a number of limitations. First, cohort differences such as differences in educational practices and speaking and writing style, as well as other motivation factors such as attentiveness or distractibility may also have contributed to the age-group differences in syntactic complexity. Second, digit span may not be the best measure of working memory. Other measures, such as Daneman and Carpenter's (1980) sentence span or those devised by Talland (1965) and Baddeley (1985) might yield different outcomes. Third, experimental manipulations of processing resources, perhaps using dual-task methodologies, are required in order to clarify cause and effect. Differences in producing and processing syntactically complex prose may contribute to a decline in working memory by contributing to elderly adults' disengagement and social isolation and, hence, cognitive stimulation. Finally, other individual differences may contribute to the loss or maintenance of working memory and syntactic complexity. Although the standard deviations reported in Tables 2, 5, and 6 do not indicate that the elderly adults were more variable than the young adults, this is a common finding in cross-sectional studies of adult age-group differences (Rowe \& Kahn, 1987). In cross-sectional designs, the effects of a variety of physiological and psychosocial factors affecting cognition may be incorrectly attributed to age. Longitudinal studies are needed.

Despite these limitations, this study reveals that language development is a life-long process of change in response to changing cognitive abilities and 
Kemper et al.: Adults' language

social motivations. Significant among these changes in adults' language are the accommodations made to memory limitations. Elderly adults appear to respond to their loss of memory capacity, not by producing more sentence fragments or relying on lexical fillers, but by restricting the syntactic complexity of their sentences. Others aspects of language seem to improve with age, among them the discourse skills required to produce clear and interesting accounts of people and events. These effects of memory and discourse genre may converge so as to reduce the syntactic complexity of elderly adults' language.

\section{ACKNOWLEDGMENTS}

A preliminary version of this article was presented at the American Speech-Language-Hearing Association annual meeting in New Orleans, November 13, 1987. A preliminary report of this research also was presented at the Mid-America Linguistics Conference, Lawrence, KS, October 18, 1987. This research was supported by grant RO1AG06319 from the National Institute on Aging to the first author.

Requests for reprints may be addressed to S. Kemper, 426 Fraser Hall, University of Kansas, Lawrence, KS 66045.

\section{REFERENCES}

Baddeley, A. D. (1985). Working memory. Oxford: Clarendon.

Beaman, K. (1984). Coordination and subordination revisited: Syntactic complexity in spoken and written narrative discourse. In D. Tannen (Ed.), Coherence in spoken and written discourse. Norwood, NJ: Ablex.

Burke, D., Worthley, J., \& Martin, J. (1988). I'll never forget what's-her-name: Aging and tip of the tongue experiences in everyday life. In M. M. Gruneberg, P. E. Morris, \& R. N. Sykes (Eds.), Practical aspects of memory: Current research and issues. Chichester: Wiley.

Chafe, W. (1982). Integration and involvement in speaking, writing, and oral literature. In D. Tannen (Ed.), Spoken and written language. Norwood, NJ: Ablex.

Chapman, R., \& Miller, J. (1984). SALT: Systematic Analysis of Language Transcripts. Madison: University of Wisconsin.

Cohen, G. (1981). Language comprehension in old age. Cognition, 9, 59-72.

Cohen, G., \& Faulkner, D. (1984). Memory for text: Some age differences in the nature of the information that is retained after listening to texts. In H. Bouma \& D. G. Bowhuis (Eds.), Attention and performance $X$. Hillsdale, NJ: Erlbaum.

Daneman, M., \& Carpenter, P. A. (1980). Individual differences in working memory and reading. Journal of Verbal Learning and Verbal Behavior, 19, 450-466.

Emery, O. (1985). Language and aging. Experimental Aging Research, 11, 3-60.

Kemper, S. (1986). Imitation of complex syntactic constructions by elderly adults. Applied Psycholinguistics, 7, 277-287.

(1987a). Life-span changes in syntactic complexity. Journal of Gerontology, 42, 323-328.

(1987b). Syntactic complexity and the recall of prose by middle-aged and elderly adults. Experimental Aging Research, 13, 47-52.

(1988). Geriatric psycholinguistics: Syntactic limitations of oral and written language. In L. Light \& D. Burke (Eds.), Language, memory, and aging. Cambridge: Cambridge University Press.

(in press). Adults' diaries: Changes to written language across the life-span. Discourse Processes.

Kemper, S., \& Rash, S. J. (1988). Speech and writing across the life-span. In M. M. Gruneberg, P. E. Morris, \& R. N. Sykes (Eds.), Practical aspects of memory: Current research and issues. Chichester: Wiley. 
Kemper et al.: Adults' language

Kroll, B. (1977). Combining ideas in written and spoken English: A look at subordination and coordination. In E. Keenan \& T. Bennett (Eds.), Discourse across time and space, Vol. 5. Los Angeles: University of Southern California Occasional Papers in Linguistics.

Kynette, D., \& Kemper, S. (1986). Aging and the loss of grammatical forms: A cross-sectional study of language performance. Language and Communication, 6, 65-72.

Obler, L. (1983). Narrative discourse style in the elderly. In L. K. Obler \& M. L. Albert (Eds.), Language and communication in the elderly. Lexington, MA: Heath.

(1985). Language through the life-span. In J. Berko Gleason (Ed.), The development of language. Columbus, $\mathrm{OH}$ : Merrill.

Ochs, E. (1979). Planned and unplanned discourse. In T. Givon (Ed.), Discourse and syntax. New York: Academic.

O’Donnell, R. C. (1974). Syntactic differences between speech and writing. American Speech, $49,102-110$.

Rowe, J. W., \& Kahn, R. L. (1987). Human aging: Usual and successful. Science, 237, 143149.

Talland, G. (1965). Three estimates of the word span and their stability over the adult years. Quarterly Journal of Experimental Psychology, 17, 301-307.

Tannen, D. (1982). The oral/literate continuum in discourse. In D. Tannen (Ed.), Spoken and written language. Norwood, $\mathrm{NJ}$ : Ablex.

Wechsler, D. (1958). The measurement and appraisal of adult intelligence. Baltimore: Williams \& Wilkins.

Zelinski, E. M., \& Gilewski, M. J. (in press). Memory for prose and aging. A meta-analysis. In M. L. Howe \& C. J. Brainerd (Eds.), Cognitive development in adulthood. New York: Springer-Verlag. 